\title{
The Affordable Care Act (2010) and its perceived impact on assisted fertility care access: Pilot data from a national sample of women's health practitioners in USA
}

\author{
Denis A Vaughan ${ }^{1}$, Irene Dimitriadis ${ }^{1}$, Eric Scott Sills ${ }^{* 2,3}$, Kelly Pagidis ${ }^{4}$ \\ ${ }^{1}$ Department of Obstetrics and Gynecology, Tufts Medical Center, Boston Massachusetts, USA \\ ${ }^{2}$ Reproductive Research Section, Center for Advanced Genetics, Carlsbad California, USA \\ ${ }^{3}$ Department of Obstetrics \& Gynecology, Palomar Medical Center, Escondido California, USA \\ ${ }^{4}$ Division of Reproductive Endocrinology \& Infertility, Department of Obstetrics and Gynecology, Women and Infants \\ Hospital/Warren Alpert Medical School, Brown University, Providence Rhode Island, USA
}

Received: December 26, 2016

Accepted: February 19, 2017

Online Published: February 27, 2017

DOI: $10.5430 /$ ijh.v3n1p63

URL: https://doi.org/10.5430/ijh.v3n1p63

\begin{abstract}
Objective: The Patient Protection \& Affordable Care Act (ACA), or "Obamacare", represents the most substantial reform of the U.S. healthcare system since the 1965 creation of Medicare and Medicaid. This investigation sought to ascertain knowledge and opinion among physicians providing women's healthcare services about how this national health program will impact access to fertility treatments.

Methods: Between May-July 2014, doctor's perceptions of ACA were registered by anonymous questionnaire submitted to program directors and house staff at 50 accredited obstetrics \& gynecology training centers in USA. Self-reported political preferences were also tabulated for each respondent.

Results: Overall, $53.3 \%$ of participants $(n=114)$ claimed familiarity with ACA although this varied significantly by seniority $(68.8 \%$ of faculty vs. $40 \%$ of trainees; $p=.003)$. Among respondents $54.9 \%$ identified as liberal, $23 \%$ as moderate, and $19.5 \%$ as conservative. Most physicians in this sample (51.8\%) anticipated a positive impact on assisted fertility care from ACA, 17.9\% predicted an adverse effect, and just under one third (30.3\%) either had no opinion or were unable to make a prediction.

Conclusions: This study offers the first analysis of women's healthcare physicians' opinion about the impact of ACA on assisted fertility services. Our report finds low general familiarity of ACA among doctors. Moreover, marked divisions of opinion exist among physicians concerning the ACA in general, as well as what role the ACA should play in the provision of assisted fertility care specifically. If U.S. physicians are to provide leadership on women's healthcare policy initiatives with a view to reach consensus (especially with respect to assisted fertility services), improved awareness of the ACA and its sequela will be crucial.
\end{abstract}

Key Words: Affordable Care Act, Insurance, In vitro fertilization, Women's health

*Correspondence: Eric Scott Sills; Email: drsills@CAGivf.com; Address: 3144 El Camino Real, Suite 106, Carlsbad CA 92008, USA. 


\section{INTRODUCTION}

The Patient Protection \& Affordable Care Act (ACA) also known as "Obamacare", represents the most substantial reform of the American healthcare system since the passage of Medicare and Medicaid in 1965. The 2010 statute was designed to help hospitals and physicians modify their practices financially, technologically, and clinically to enable improved health outcomes at lower cost. A fundamental element of the ACA requires insurance companies to cover applicants within new minimum standards and offer the same rates, regardless of the presence of any pre-existing conditions or sex. ${ }^{[1]}$

The ACA incorporates certain standards for insurance companies to follow immediately, while other regulations were to be introduced later at the discretion of the Secretary of Health and Human Services. These new rules under the ACA included a ban on the ability to cancel an insurance policy if the insured individual became sick, a prohibition on price discrimination based on any pre-existing medical condition (or sex), and allowing children and dependents to remain on a parent's insurance plan until their 26th birthday. While mammograms, FDA-approved contraceptives, breastfeeding support and supplies, and domestic violence screening and counseling were welcomed as important elements for women's health care services, ${ }^{[2]}$ the ACA made no specific provision for the advanced reproductive technologies. ${ }^{[3]}$

Independent of the ACA, 15 states currently have mandates which require employers to provide insurance with coverage for some fertility treatments. Of these states, only seven (Arkansas, Connecticut, Hawaii, Illinois, Maryland, Massachusetts, and New Jersey) require that in vitro fertilization (IVF) be specifically included as a health benefit. Of note, Arkansas limits this benefit to $\$ 15,000$ and Hawaii requires insurance coverage for just one IVF cycle. The most inclusive state for IVF coverage is Massachusetts with up to six IVF cycles. However, substantial exclusions and restrictions can mean that fertility patients will still end up paying out-of-pocket for major components of treatment.

Reproductive health services have long been a contentious issue within American health care reform, and it remained a difficult concept for the ACA as this legislation coalesced. The United States Supreme Court's decision affirming the constitutionality of the ACA has kept this issue relevant for patients and physicians. Although the ACA may be modified, repealed, or replaced in the future, in its present form the legislation does not include any coverage guarantees for even the most basic fertility treatments. But does government have an interest in the provision of this elective medical service? And if it does, how do current doctors in USA who would be best positioned to offer or suggest assisted fertility treatment regard the ACA and its impact on access to this type of care? This investigation is the first to collect information on the ACA directly from physicians providing women's health services.

\section{Methods}

A one page research questionnaire was sent by email to obstetrics \& gynecology residency program directors $(n=50)$ at ABOG-approved training facilities between May-July 2014. Contact details for each invitation were obtained from the current Association of Professors of Obstetrics \& Gynecology (APGO) directory, with participants selected randomly. While APGO represents academic obstetrician-gynecologists in USA and Canada, for the purposes of this study questionnaires were restricted to USA recipients. Once delivery receipt was confirmed, program directors were invited to distribute the questionnaire to faculty, fellows (reproductive endocrinology \& infertility), and house staff to complete on a voluntary basis. When volunteers $(n=15)$ pre-tested the 13-item study questionnaire, average time required to complete the survey was $10 \mathrm{~min}$. A summary of queried items is shown in Table 1. Questionnaire data were assessed by investigators and categorized for assignment when answers other than "yes/uncertain/no" were submitted. Responses for questionnaire items were given as "positive/neutral/negative" as appropriate, and personal political view was selected as either liberal, moderate, or conservative (collected for future research). Responses were electronically tracked to block duplicate submissions from the same individual. Because responses were reported in a non-identifiable manner and specific institutions were doctors worked were not reported, there was no danger that participants might suffer disciplinary consequences. Only investigators were permitted access to running totals of the questionnaire during the study. Because this study was based on data derived from an anonymous survey submitted to physicians only and did not collect any protected health information, the research protocol was judged as "no risk to human subjects"; IRB oversight was therefore offered but not required. Chi-square/contingency table and Fisher's exact tests were used, as appropriate. $P$ values $<.05$ were considered significant.

\section{Results}

A total of 114 survey responses from 24 states were provided by attending faculty $(n=52)$, fellows $(n=9)$, and residents ( $n=53$ ). From all respondents, $53.3 \%$ of physicians considered themselves to be familiar with the ACA (see Table 2 ), although this varied significantly as a function of training level (i.e., $68.8 \%$ of faculty vs. $40 \%$ of trainees; $p=$ .003). The number of responses obtained from individuals 
based in a state with an infertility insurance mandate was similar to the number received from non-mandated jurisdictions (11 vs. 13, respectively). Among respondents $54.9 \%$ self-identified as liberal, $23 \%$ as moderate, and $19.5 \%$ as conservative. Most (51.8\%) considered the ACA would have a positive impact on overall patient care, while $17.9 \%$ predicted an adverse effect. When ACA impact was estimated across the three areas of physician practice, overall patient care and infertility practice, the highest level of respondent uncertainty was registered in the latter category (see Table 3). Of note, there was a significant difference between generalist OBGYNs and subspecialty reproductive endocrinology (REI) fellows with respect to perceived ACA impact on provision of fertility coverage within states already mandating this benefit after 2016. A change in such coverage was predicted by $19.7 \%$ and $58.3 \%$ of generalists and REI fellows, respectively $(p<.05)$. Moreover, many generalists $(59.2 \%)$ indicated that they were uncertain if there would be modifications in infertility coverage after 2016. When these physicians were queried about whether the ACA should cover infertility treatments after $2016,33.8 \%$ of generalists and $69.2 \%$ of REI respondents felt that treatments should be included as an insurance health benefit.

Table 1. Summary of queries submitted to women's health physicians $(n=114)$ regarding perceptions of the ACA and its impact on local provision of assisted fertility services

\begin{tabular}{|l} 
1. Where is your current state of practice located (or training, if not yet in independent practice)? \\
2. Do you consider yourself familiar with the provisions of the ACA? \\
3. How would you categorize your own personal political view or philosophy? \\
4. What do you think is the overall impact of the ACA on patient healthcare for your practice or training? \\
5. What do you think that the ACA's overall impact on U.S. physicians' practice (in general) will be? \\
6. Do you currently practice/train in a state where infertility treatment is covered by a state mandate? \\
7. Do you consider yourself familiar with the healthcare mandate in your state (if applicable)? \\
8. Do fertility treatments fall under the essential health benefits (EHB) as defined by the ACA? \\
9. After 2016, do you think that the ACA will affect mandated states' coverage of infertility treatments? \\
10. Do you consider current infertility coverage (as it currently exists in mandated states) is sufficient? \\
11. Do you think that infertility treatments should be covered by the ACA after 2016? \\
12. What do you think that the ACA's overall impact on infertility patients will be? \\
13. What do you think the ACA's overall impact on physician's practice who treat infertility will be? \\
14. In your opinion, will the ACA have any impact on wait times for patients to see REI specialists?
\end{tabular}

Notes. ACA = Affordable Care Act, 2010

Table 2. Summary of survey responses from U.S. women's health physicians $(n=114)$ regarding perception of ACA impact on service delivery and office operations

\begin{tabular}{llllll}
\hline \multirow{2}{*}{ Parameter } & \multirow{2}{*}{ Total responses (n) } & \multicolumn{4}{c}{ Impact perceived by physicians (\%) } \\
\cline { 3 - 6 } & & Positive & Neutral & Negative & Uncertain \\
\hline Access to infertility services & 106 & 17.9 & 28.4 & 16.0 & 37.7 \\
Overall patient care & 112 & 51.8 & 10.7 & 17.9 & 19.6 \\
Physician practice & 106 & 18.9 & 21.7 & 37.7 & 21.7 \\
\hline
\end{tabular}

Notes. ACA = Affordable Care Act, 2010 (“Obamacare”). Not all respondents answered every question.

Next, an analysis of perceived impact of the ACA on physician practice after stratifying by personal political views was undertaken. Among those who identified as liberal, 75\% stated that ACA would have a positive effect on access to assisted fertility services while no self-described conservative respondent reported this opinion $(43.4 \%$ did not know or supplied no response).

Survey responses were further analyzed according to geographical origin (i.e., location of practice or training) with a view to identify potential differences between states with

Published by Sciedu Press

a current mandate requiring assisted fertility coverage vs. those states which do not. Of note, there was no significant difference between the two geographical groups with respect to self-reported ACA knowledge, the perceived impact of the ACA on health care or the impact ACA is likely to have on physicians' practice. Overall, 12 respondents (11.3\%) felt that the ACA would have a desirable impact on physicians' practice, whereas $32(30.2 \%)$ stated that the ACA will have a harmful effect. and 46 (43.4\%) stated that they didn't know what effect the implementation of the ACA would have on their practice. 
Table 3. Summary of self-reported ACA knowledge and impact of the ACA on access to assisted fertility care among women's health physicians ( $n=114)$

\begin{tabular}{lllll}
\hline \multirow{2}{*}{ Query } & Total & \multicolumn{3}{c}{ Response (\%) } \\
\cline { 2 - 5 } & responses ( $\boldsymbol{n}$ ) & Yes & No & Uncertain \\
\hline $\begin{array}{l}\text { Are you familiar with } \\
\text { ACA? }\end{array}$ & 107 & 53.3 & 46.7 & 0 \\
$\begin{array}{l}\text { Will ACA affect } \\
\text { fertility coverage? }\end{array}$ & 107 & 23.4 & 23.4 & 53.3 \\
$\begin{array}{l}\text { Is current fertility } \\
\text { coverage sufficient? }\end{array}$ & 108 & 39.8 & 26.9 & 33.3 \\
$\begin{array}{l}\text { Should ACA cover } \\
\text { fertility services? }\end{array}$ & 109 & 40.4 & 45.0 & 14.6 \\
\hline $\begin{array}{l}\text { Notes. ACA = Affordable Care Act, 2010 (“Obamacare”). Not all respondents } \\
\text { answered every question. }\end{array}$ & & & & \\
\end{tabular}

\section{Discussion}

The arrival of the ACA (informally known as "Obamacare") on the American healthcare landscape in 2010 was marked by intense interest and diverse discussion across a range of medical and surgical providers in USA. Although the legislation was endorsed by the American Medical Association and many primary care organizations, the American College of Surgeons and numerous other surgical groups strongly opposed the bill. The observed divergence likely derived from opposition to particular ACA provisions which were considered to have differing implications for physicians represented by certain organizations, as well as the relative importance of provisions for which these organizations shared a common opinion. ${ }^{[4]}$ While this sentiment has been studied among family practitioners, ${ }^{[5]}$ otolaryngologists, ${ }^{[6]}$ plastic surgeons, ${ }^{[4]}$ dentists, ${ }^{[7]}$ pharmacists, ${ }^{[8]}$ and medical students, ${ }^{[9]}$ the present study is the first to assess this issue specifically among those providing healthcare exclusively for women; it is also the first to focus specifically on the intersection of assisted fertility care and the ACA.

Other investigators have cautioned that while the ACA's emphasis on maternity care represents a welcome theme in public health policy, it remains to be seen if this legislation will meaningfully alter access to fertility care for patients seeking this service in USA. ${ }^{[10]}$ Insurance rules governing eligibility for fertility treatment may be seen as occupying common policy terrain with access to abortion-both characterized as controversial and with an unclear future going forward. Recognizing this uncertainty, and given the current political momentum which aims to repeal/replace the ACA, our research was envisioned as an initial step to gather data on the present insurance implications for assisted fertility care as observed by those best able to report on this phenomenon women's healthcare physicians.

Several aspects of this investigation bring forward new data 66 on the intersection of assisted fertility services and insurance cover in USA. First, we found that the overall fund of knowledge concerning the ACA among women's health physicians was fair at best (53.3\%), and those still in training reported even lower familiarity (40\%). Likewise, nearly $60 \%$ of generalists acknowledged uncertainty about how the ACA might impact infertility coverage after this year. Perhaps not surprisingly, those involved in subspecialty (reproductive endocrinology) practice were far more likely to favor fertility services being included as a basic ACA benefit going forward. Nevertheless, physician sentiment and opinion alone will be ineffective levers to influence federal health policy without full engagement with the legislative process with a view to articulate why these services are so important.

Our research has some limitations which require comment. First, these are pilot data derived from a limited sample of American academic practitioners and our findings may not generalize to all women's health providers in USA. In addition, it has been established that conducting surveys among physicians is not the same as collecting information from the general population. ${ }^{[11]}$ Because an invitation to fill out a questionnaire may not be viewed any differently than other demands on a physician's time, response rates for doctors are lower than for similar studies in other settings. ${ }^{[12]} \mathrm{We}$ attempted to overcome this by targeting program directors as the primary contact, enlisting their leadership to induce others at their institutions to provide data for analysis. However because the absolute faculty size at each training unit was not known with precision, it was not possible to calculate an exact response rate for this survey without this denominator. Importantly, for this study ACA knowledge was self-reported and could not be independently validated. Additional investigation will be required to determine if the actual level of ACA knowledge among physicians in USA was different than reported here. Moreover, if physicians have a persistent knowledge gap about a mandated national health plan in place since 2010, it is concerning that this low level of familiarity will persist with an ACA successor (if any).

This pilot study nevertheless presents an original contribution to contemporary understanding of insurance cover and how the ACA is viewed by women's health physicians. Despite the widespread and growing use of assisted fertility services in USA, here this treatment remains largely privately funded. The association between state mandates for infertility insurance coverage and increased local utilization of assisted reproduction treatment ${ }^{[13]}$ suggests that comparable federal legislation would likewise result in higher consumption of such services nationwide. The trajectory U.S. health care reform may still be shaped by input from physicians, who, when intelligently engaged, can bring the necessary aptitude 
and interest in these women's healthcare issues. The current research informs areas where those efforts may be best focused, and helps shape the basis of investigative work going forward.

\section{Disclosure}

These data were presented in part at the 63rd annual meeting of the Pacific Coast Reproductive Society; Rancho Mirage, California (March 11-15, 2015).

\section{AUTHOR CONTRIBUTIONS}

DAV was primary investigator and conceived of the research; ID, ESS and KP assisted in data analysis and manuscript development. All authors read and approved the final submission.

\section{Conflicts of InTEREST Disclosure}

The authors declare no conflict of interest.

\section{REFERENCES}

[1] USGPO. U.S. Public Law 111-148. Washington, D.C.: March 23, 2010.

[2] National Law Review. Next Steps to Comply with Health Care Reform. Available from: http://www.natlawreview.com/a rticle/next-steps-to-comply-health-care-reform. October 10, 2012, Retrieved July 24, 2013.

[3] Sills ES. An evidence-based policy for the provision of subsidised fertility treatment in California: integration of array comparative genomic hybridisation with IVF and mandatory single embryo transfer to lower multiple gestation and preterm birth rates [PhD' $\mathrm{s}$ thesis]. British Library EthOS: Univ Westminster-London; 2013. EThOS ID: uk.bl.ethos.576982.

[4] Abbott MM, Meara JG. Patient Protection and Affordable Care Act: implications for pediatric plastic surgery. J Craniofac Surg. 2012; 23(1): 217-9. PMid: 22337412. https ://doi.org/10.1097/SC S. 0b013e318241b8a4

[5] Petterson S, Bazemore AW, Phillips RL, et al. Rewarding family medicine while penalizing comprehensiveness? Primary care payment incentives and health reform: the Patient Protection and Affordable Care Act (PPACA). J Am Board Fam Med. 2011; 24(6): 637-8. PMid: 22086805. https ://doi .org/10.3122/jabfm.2011.06. 110172

[6] Sun GH, Davis MM. The Patient Protection and Affordable Care Act of 2010: impact on otolaryngology practice and research. Otolaryn- gol Head Neck Surg. 2012 May; 146(5): 690-3. PMid: 22282865. https://doi.org/10.1177/0194599811435967

[7] Oneacre LP. How the Patient Protection and Affordable Care Act affects Texas dentists. Tex Dent J. 2012; 129(10): 1106-9. PMid: 23311030.

[8] Khanna R, Mahabaleshwarkar R, Holmes ER, et al. Pharmacists' perspectives on the Patient Protection and Affordable Care Act. Res Social Adm Pharm. 2015; 11(1): 111-20. PMid: 24846579. https://doi.org/10.1016/j.sapharm.2014.04.003

[9] Huntoon KM, McCluney CJ, Scannell CA, et al. Healthcare reform and the next generation: United States medical student attitudes toward the Patient Protection and Affordable Care Act. PLoS One. 2011; 6(9): e23557. PMid: 21931604. https ://doi .org/10.137 1 /journal.pone. 0023557

[10] Omurtag K, Adamson GD. The affordable care act's impact on fertility care. Fertil Steril. 2013; 99(3): 652-5. PMid: 23137761. https://doi.org/10.1016/j.fertnstert.2012.10.001

[11] Flanigan TS, McFarlane E, Cook S. Conducting survey research among physicians and other medical professionals - a review of current literature. AAPOR Sec Surv Res Methods. 2008; 4136-46.

[12] Cummings SM, Savitz LA, Konrad TR. Reported response rates to mailed physician questionnaires. Health Serv Res. 2001; 35(6): 1347-55. PMid: 11221823.

[13] Jain T, Harlow BL, Hornstein MD. Insurance coverage and outcomes of in vitro fertilization. N Engl J Med. 2002; 347: 661-6. PMid: 12200554. https://doi.org/10.1056/NEJMsa013491 